\title{
Educación superior, innovación y docencia: alcances y limitaciones de la virtualidad como estrategia institucional
}

\author{
Higher Education, Innovation and Teaching: Scope and Limitations of \\ Virtuality as an institutional strategy
}

Ensino superior, inovação e ensino: alcance e limitações da virtualidade como estratégia institucional

\author{
José Ricardo López Espinosa \\ Universidad de Sonora, México \\ josericardoloes@gmail.com \\ https://orcid.org/0000-0002-1936-1629 \\ Edgar Oswaldo González Bello \\ Universidad de Sonora, México \\ edgar.gonzalezb@unison.mx \\ https://orcid.org/0000-0001-6297-2516
}

\section{Resumen}

Este texto presenta los resultados de una indagación en una institución de educación superior en la que, a partir del año 2015, bajo la intención de mejorar los indicadores de calidad educativa, y en especial los de cobertura, se sustituyeron horas de clases presenciales por el empleo de una plataforma virtual en las asignaturas de todos sus programas de estudio. El objetivo que atiende este análisis se orienta a analizar las limitaciones que, desde la perspectiva del profesorado, caracterizan la enseñanza a través de tecnologías en una universidad pública estatal de México. Esto a través de un diseño cualitativo, un enfoque fenomenológico y la aplicación de una entrevista semiestructurada a 32 docentes adscritos a la institución. Los resultados ponen en evidencia principalmente tres situaciones: la sensación de incertidumbre respecto al uso de la plataforma virtual, el aparente desinterés por 


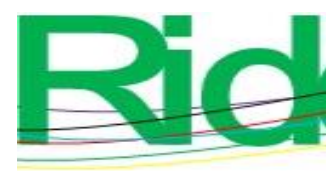

Revista Iberoamericana para la
Investigación y el Desarrollo Educativo
ISSN $2007-7467$

implementar nuevas estrategias didácticas y la inquietud por un incentivo al ejercicio docente en la virtualidad. En consecuencia, se advierte la necesidad de promover el uso correcto de la plataforma virtual a través de programas de estímulos institucionales. Asimismo, se sugiere a la institución fomentar el desarrollo de estrategias didácticas acordes a los medios con los que dispone cada docente, ya que de no lograrse lo señalado será complicado asumir a la enseñanza a través de tecnologías como una innovación exitosa.

Palabras clave: enseñanza virtual, profesores, TIC.

\section{Abstract}

This text presents the results of an investigation in a higher education institution where, as of 2015, under the intention of improving educational quality indicators - and especially coverage - hours of face-to-face classes were replaced by the use of a virtual platform in the subjects of all its study programs. The objective of this analysis is aimed at analyzing the limitations that, from the teacher's perspective, characterize teaching through technology in a state public university in Mexico. This through a qualitative design, a phenomenological approach and the application of a semi-structured interview to 32 teachers attached to the institution. The results mainly reveal three situations: the feeling of uncertainty regarding the use of the virtual platform, the apparent lack of interest in implementing new didactic strategies and the concern for an incentive to teach in virtuality. Consequently, there is a need to promote the correct use of the virtual platform through the institutional stimulus program. Likewise, the institution is suggested to promote the development of didactic strategies according to the means available to each teacher, since if the aforementioned is not achieved, it will be difficult to assume teaching through technologies as a successful innovation.

Keywords: virtual learning, teachers, ICT. 


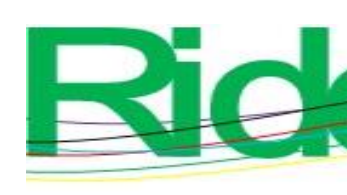

Revista Iberoamericana para la Investigación y el Desarrollo Educativo ISSN $2007-7467$

\section{Resumo}

Este texto apresenta os resultados de uma investigação em uma instituição de ensino superior em que, a partir de 2015, com o intuito de melhorar os indicadores de qualidade educacional, e principalmente os indicadores de cobertura, a carga horária foi substituída pela utilização de plataforma virtual nas disciplinas de todos. seus programas de estudo. O objetivo desta análise é analisar as limitações que, na perspectiva do professor, caracterizam o ensino por meio da tecnologia em uma universidade pública estadual no México. Trata-se de um desenho qualitativo, de uma abordagem fenomenológica e da aplicação de uma entrevista semiestruturada a 32 professores vinculados à instituição. Os resultados revelam principalmente três situações: o sentimento de incerteza quanto ao uso da plataforma virtual, o aparente desinteresse em implementar novas estratégias didáticas e a preocupação com o incentivo ao ensino na virtualidade. Consequentemente, é necessário promover o uso correto da plataforma virtual por meio de programas de estímulo institucional. Da mesma forma, sugere-se que a instituição promova o desenvolvimento de estratégias didáticas de acordo com os meios à disposição de cada professor, uma vez que, se isso não for alcançado, será difícil assumir o ensino por meio das tecnologias como uma inovação de sucesso.

Palavras-chave: ensino virtual, professores, TIC.

Fecha Recepción: Abril 2021

Fecha Aceptación: Octubre 2021

\section{Introducción}

Desde sus inicios, las instituciones de educación superior han ofrecido formación profesional a los individuos en tanto que su funcionamiento mantiene una conexión directa con las necesidades de la sociedad (Altbach, 2008). No obstante, las exigencias y demandas de la sociedad - desde siempre - han sido heterogéneas y cambiantes, de tal forma que las organizaciones educativas han requerido adaptarse a través del tiempo mediante diferentes estrategias para hacer pertinente su oferta (Guzmán, Muñoz, Álvarez y Velázquez, 2009).

En ese sentido, y debido a los efectos de la globalización, un reto significativo para la educación superior ha sido la incorporación de las tecnologías de información y comunicación (TIC), entendidas como medios de apoyo con el potencial de contribuir a la diversificación y mejoramiento de los procesos de enseñanza-aprendizaje. Esto ha favorecido la configuración de nuevas formas de ofrecer educación con el empleo de tecnologías digitales (Ramírez y Casillas, 2014). Así, las universidades han tenido la posibilidad de 


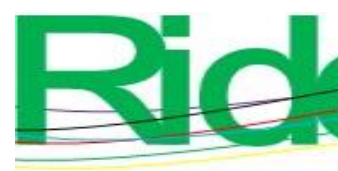

Revista Iberoamericana para la
Investigación y el Desarrollo Educativo
ISSN $2007-7467$

ampliar el acceso a la información que se produce de manera global, además de proponer nuevas alternativas para enfrentar los problemas (cobertura y calidad) de la educación presencial, específicamente el asunto de flexibilidad que demanda la formación profesional (Silvio, 2006).

En atención a estas intenciones, desde fines de los años 90 existió una tendencia por virtualizar la educación superior, lo cual significó la implementación de tecnologías y recursos digitales en los métodos de enseñanza y aprendizaje de la educación presencial; también la reconfiguración de la educación a distancia como educación virtual (Rama, 2012). Según Chan (2016), la virtualización de la educación demanda una integración entre los entornos de aprendizaje físicos y digitales, considerando que, entre unos y otros, hay mediación de las tecnologías para la representación o evocación de los objetos de conocimiento y el modelamiento de interacciones para el aprendizaje.

Esta tendencia contribuyó a que las universidades, además de invertir en infraestructura tecnológica, se apegaran a la intención de generar conocimientos y habilidades en los estudiantes para utilizar efectivamente las tecnologías en el acceso y el manejo de la información (Organización para la Cooperación y el Desarrollo Económico [OCDE], 2016). Mientras algunas universidades optaron por adquirir este tipo de recursos, con la intención de reconfigurar el ejercicio docente, otras implementaron programas de educación virtual. En todos los casos, se han implementado las tecnologías como parte del conjunto de innovaciones educativas sugerido por diversos organismos internacionales, con el supuesto de mejorar la calidad de la enseñanza.

De esta forma, las universidades han transitado hacia un contexto, desde la perspectiva internacional, donde la educación presencial apoyada por tecnologías permite la posibilidad de generar cambios positivos e innovadores en la enseñanza (Organización de las Naciones Unidas para la Educación, la Ciencia y la Cultura [Unesco], 2006). Sin embargo, los logros de las tecnologías en la educación siguen pareciendo dudosos y cuestionables debido a que se desconoce, en términos generales, de qué forma el ejercicio docente a través del uso de estas ha resultado favorecido, o si solo se ha tratado de una simulación. De ahí la pertinencia de indagar en el tema desde una visión cualitativa: explorar con mayor profundidad la experiencia y las percepciones de los actores, y por lo tanto, ir más allá de la descripción de un conjunto de indicadores (Sautu, Boniolo, Dalle y Elbert, 2005). 


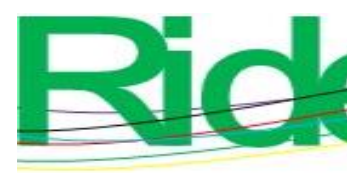

Revista Iberoamericana para la Investigación y el Desarrollo Educativo ISSN $2007-7467$

En cuanto a los actores, se ha reconocido que el papel desempeñado por directivos y docentes en la implementación de tecnologías para la enseñanza es clave para la concepción de los objetivos que se esperan alcanzar. Las instituciones enfrentan la necesidad de ofrecer una formación al personal docente que le permita emplear favorablemente las tecnologías. Para ello, por supuesto, también requieren de personal directivo caracterizados por un liderazgo y un pensamiento crítico para promover de manera adecuada esta implementación (Ducoing, 2003; Hannan y Silver, 2005). Precisamente, el problema de la educación presencial mediada por tecnologías se relaciona con estos planteamientos.

Según Allen y Gupta (2018), existe un liderazgo simulado que afecta a todas las instituciones debido a que los directivos se limitan a repetir los discursos de las propuestas de los rectores o de los lineamientos establecidos en políticas institucionales. En efecto, la falta de participación crítica de los actores involucrados afecta negativamente. En suma, no basta con disponer de los más modernos medios; también es necesario crear una cultura que fomente el cambio en las mediaciones pedagógicas, la superación de una enseñanza por exposición y aprendizaje por recepción, junto con la implementación de nuevos paradigmas de aprendizaje activo e interactivo. Además, es necesario que la formación docente permita a los profesores comprender cómo aprovechar las tecnologías para transformar positivamente la enseñanza en el aula (Marcelo, 2013).

Según datos de Silvio (2006), la educación virtual se ha incrementado a partir de la llegada del siglo XXI, pues $10 \%$ de los estudiantes de posgrado en América Latina en el año 2003 recibía clases en educación virtual y 175 instituciones contaban con programas de educación virtual para pre y posgrado. Los beneficios propuestos por este tipo de modalidades apuntaban a ampliar la cobertura ante un costo menor por estudiante en comparación con la educación presencial tradicional. Sin embargo, desde un enfoque curricular basado en competencias profesionales, la educación virtual no ha conseguido formar en igualdad de calidad todas las competencias que se proponen. Además, la educación virtual puede significar la implementación de modelos homogéneos con poca calidad, flexibles en extremo y centrados en la enseñanza, sin prácticas ni movilidad, y sin sistemas de mejoramiento de la calidad, pertinencia o reflexividad intelectual (Rama, 2012).

En este contexto, se adscribe un tipo distinto de modalidad educativa, que implica actividades propias de la educación virtual y del formato presencial, pero pedagógicamente estructuradas para el logro de las competencias/objetivos; además de sesiones presenciales, 


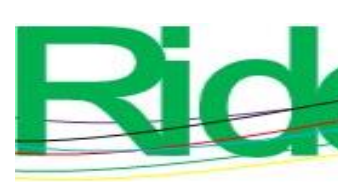

Revista Iberoamericana para la
Investigación y el Desarrollo Educativo
ISSN $2007-7467$

incluye combinar, integrar y complementar la educación con materiales y recursos tecnológicos. Presupone la posibilidad práctica de aprovechar toda ocasión programada didácticamente (curso/módulo/asignatura) para mezclar métodos tecnopedagógicos (Turpo, 2012). Esto se alude al concepto de educación semipresencial o b-learning, implementada en algunas instituciones como una especie de antesala para la implementación de un modelo de educación virtual y en otras como un tipo de modalidad permanente que es producto de la evolución de dos formas distintas de ofrecer educación.

Generalmente, el b-learning se ha implementado en México con el objetivo de combinar los beneficios de la educación virtual en términos de flexibilidad, cobertura y reducción de costos por estudiante con las virtudes de la educación presencial: interacción estudiante-docente y retroalimentación. Es una modalidad que, si bien logra retomar los beneficios de la educación virtual y la presencial, también parece mantener algunos de los problemas de ambas modalidades de enseñanza. Algunas investigaciones (Díaz-Barriga, 2020; Ruiz, 2020) han encontrado que los estudiantes perciben de mejor manera la enseñanza desde una modalidad presencial a diferencia de una semipresencial; otras aproximaciones (Cobo, 2019; López, González y López, 2018) han reconocido que los profesores necesitan una mejor formación para trabajar con el uso de tecnologías en la docencia. Entonces, ¿se podría considerar que la implementación de tecnologías en diversas modalidades educativas permite la innovación de la enseñanza?

\section{Innovación educativa y el rol de las tecnologías en la enseñanza}

A nivel global, las universidades han pasado por diferentes transformaciones. Desde hace más de tres décadas, uno de los principales problemas se debió a un incremento masivo y descontrolado de la matrícula de estudiantes que ingresaban a la educación superior, lo cual ocasionó inestabilidad y una idea generalizada de que la universidad no respondía a las demandas de la sociedad. Debido a esto, las instituciones se vieron estancadas en problemas políticos internos; a la necesidad de elevar la calidad y a la de continuar elevando la matrícula (De Vries, 2005).

Durante esos mismos años, el Gobierno mexicano también consideró necesario extender la cobertura, además de poner énfasis en los asuntos de calidad educativa, lo cual propició la implementación de políticas públicas con el fin de repercutir positivamente en el desempeño de sus instituciones. A nivel nacional, se promovió e institucionalizó el cambio 


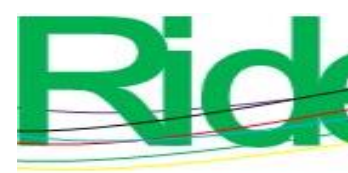

Revista Iberoamericana para la
Investigación y el Desarrollo Educativo
ISSN $2007-7467$

educativo por primera vez con el Programa para la Modernización Educativa (1989-1994), el cual mantuvo el supuesto de impulsar la calidad de los programas educativos mediante la innovación y la evaluación permanente de las instituciones (Rubio, 2006).

Desde entonces, el funcionamiento de las instituciones de educación superior ha sido regulado e influenciado por diversos organismos y programas derivados de la política pública, la cual se traduce como un conjunto de planes, estrategias y acciones que buscan modificar el sistema según un diseño explícito de prioridades y objetivos. Desde el contexto nacional, las políticas advierten y enfatizan en la innovación como un eje para mejorar la calidad; sin embargo, tal y como advierte Rodríguez (2002), al analizar estas políticas es necesario superar la descripción del discurso gubernamental, principalmente porque el sistema se integra con instituciones públicas y privadas que poseen su propia autonomía.

Diversos organismos internacionales también han propuesto alcanzar una educación con calidad y aprovechar el desarrollo de los avances tecnológicos para incrementar la cobertura y ofrecer una mejor enseñanza (Unesco, 2016). De ahí que las instituciones educativas en México se encuentran principalmente orientadas a optimizar los indicadores relacionados con la calidad y la cobertura, sin descuidar la recomendación de incluir a las tecnologías para innovar en sus modelos educativos. Así, cada establecimiento plantea innovaciones que pueden ser muy diversas, pero que en cada caso apuntan a los objetivos y metas institucionales. Esto permite comprender que la innovación educativa representa un proceso para generar acciones con la intención de cambiar para mejorar, y cuyos resultados pueden ser muy variados.

Las implicaciones de cada innovación, por lo tanto, pueden ser bastante diversas según el contexto que pretenda modificar y de los actores que se encuentren involucrados en el cambio (Fullan y Stiegelbauer, 2011). Esto hace pertinente observar las innovaciones educativas como estudios de caso, con la finalidad de identificar planteamientos, planes y objetivos institucionales, y desde este marco de referencia reconocer los resultados que se generan en la innovación, así como posibles focos de atención al momento de implementar un cambio.

En México, uno de los acontecimientos más importantes de cambio fue la configuración del sistema de educación superior que se suscitó a partir de la expansión de matrícula en la década de los años 70. Esta expansión fue apoyada por una mayor asignación de recursos dirigidos a desarrollar y crear nuevas instituciones educativas, lo cual permitió 


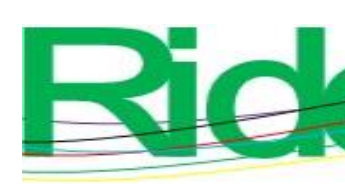

Revista Iberoamericana para la
Investigación y el Desarrollo Educativo
ISSN $2007-7467$

mayor acceso a la educación a una población creciente y diversa. Sin embargo, este periodo también se caracterizó por una ausencia de políticas que contribuyeran a un impacto positivo en la calidad de los programas educativos (Mungaray, Ocegueda, Moctezuma y Ocegueda, 2016), por lo que la educación superior de México se ha caracterizado a la fecha por la heterogeneidad y diversidad de instituciones (Rubio, 2006).

En 1978 se creó un nuevo tipo de institución en el subsistema de universidades públicas estatales: las universidades públicas estatales con apoyo solidario (Upeas). Fue hasta el año de 1994 cuando se impulsó mayormente la creación de este tipo de instituciones. Las Upeas fueron creadas por decreto de congresos locales y bajo la figura jurídica de organismos públicos descentralizados. Reciben un subsidio federal complementario al que otorgan los gobiernos estatales, y pueden establecer sus propios tabuladores y programas de estímulos (Mendoza, 2015). Están orientadas a desarrollar funciones de docencia, generación y aplicación innovadora del conocimiento, además de extensión y difusión de la cultura. Sin embargo, debido a la diversidad de sus modelos educativos, oferta y políticas institucionales, el funcionamiento de estas instituciones varía de gran manera al de una universidad.

Existen 25 instituciones de este tipo que, en conjunto, ofrecen formación profesional a $1.6 \%$ de estudiantes mexicanos; por supuesto, a lo largo del tiempo se han enfocado a incrementar sus indicadores de cobertura. Pero, ¿cómo es el funcionamiento de las Upeas? ¿En qué medida se asemejan o diferencian sus características con las de otras instituciones? De acuerdo con Mejía (2016), es escasa la información que se tiene sobre este tipo de instituciones, por lo que recomienda indagar en torno a estas, pero analizando casos particulares, de tal forma que los resultados obtenidos se puedan comparar con otras instituciones de este tipo.

En Sonora, una de las instituciones públicas es la Universidad Estatal de Sonora (UES). Fue fundada en 1983 tras los esfuerzos realizados por el Gobierno estatal para diversificar la matrícula (Rodríguez, Treviño y Urquidi, 2007) con el nombre de Centro de Estudios Superiores del Estado de Sonora (Cesues). Es una UPEA que está orientada a ofrecer formación profesional para impulsar las áreas prioritarias de desarrollo de la región. Desde sus inicios, esta universidad se ha enfocado en incrementar la matrícula de estudiantes y mejorar la calidad educativa.

Asimismo, al revisar sus antecedentes, se pueden detectar diversos cambios y un impulso a las innovaciones. Lo más sobresaliente recae en lo referente a su población escolar 


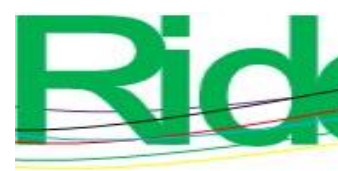

Revista Iberoamericana para la Investigación y el Desarrollo Educativo ISSN $2007-7467$

estudiantil, ya que, si bien la institución estuvo constantemente incrementando su matrícula, en el ciclo escolar 2005-2006 la población fue menor en comparación con años anteriores. En torno a esto, la institución ha expuesto que la cantidad de estudiantes admitidos se limitó por la falta de infraestructura física, además de los resultados insuficientes en cuanto a indicadores de calidad educativa (Espinosa, 2013).

A esto problemas institucionales, se añadió la idea sobre los programas de estudio y su obsolescencia, motivo que originó el desarrollo de un proyecto para la configuración de un nuevo modelo educativo denominado Enface, el cual estaba enfocado en el aprendizaje del estudiante y en un sistema de evaluación por competencias; también proponía ofrecer educación apoyada por tecnologías - y en especial el uso de plataformas educativas - en modalidades alternativas a la presencial para la totalidad de los programas y asignaturas. Sin embargo, y a pesar de que la implementación de las tecnologías en la enseñanza a través del modelo educativo de la UES es mencionada en los informes del rector como un caso de éxito (Huerta, 2016), hay indicadores que no se han logrado mejorar, tal y como el índice de titulación de estudiantes (57\%) o la eficiencia terminal que del 2013 al 2016 decreció 20 puntos porcentuales. Si bien los objetivos en cuanto al incremento de cobertura se alcanzan, los que tienen que ver con calidad educativa parecen estar pendientes.

En ese sentido, el objetivo de este texto se encuentra orientado a analizar, desde la perspectiva del profesorado, las limitaciones de la enseñanza no presencial apoyada de tecnologías en una universidad pública estatal en México. Esta indagación utiliza la perspectiva teórica de la innovación educativa, ya que esto permite reconocer la influencia que puede tener el cambio educativo en los actores. Según De la Torre (1998), en la tarea de describir un cambio educativo a través del desarrollo de una innovación es pertinente reconocer que se pueden generar transformaciones en diferentes sentidos dentro de un mismo contexto, ya que la innovación tiene diferentes enfoques. Consecuentemente, se propone un modelo de análisis que integra tales visiones, lo cual permite observar a la innovación como un proceso aunado a factores sociopolíticos, tecnológicos y culturales que se relacionan con el desarrollo del cambio y generan diferentes concepciones en los actores involucrados. 


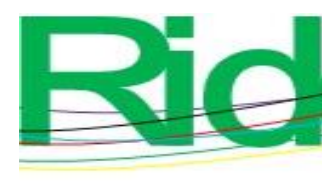

Revista Iberoamericana para la
Investigación y el Desarrollo Educativo ISSN $2007-7467$

\section{Material y métodos}

Es un estudio de corte cualitativo que, desde la perspectiva del paradigma interpretativo y mediante un enfoque fenomenológico, indaga en las experiencias de un grupo de individuos acerca de un fenómeno (Creswell, 2009). En este caso: la enseñanza a través de tecnologías y las limitaciones desde la perspectiva del profesorado. El contexto de la investigación fue la UES, institución inscrita en el subsistema de universidades estatales con apoyo solidario del sistema mexicano de educación superior y ubicada en el noroeste del país. Se recurrió a la entrevista semiestructurada como técnica para la recolección de datos, con la finalidad de identificar nuevos elementos a través de la información arrojada por cada informante.

Con la intención de recuperar información acorde a las características contextuales, se llevó a cabo una indagación a través de un acercamiento inicial con docentes que tuvieron la oportunidad de expresar ideas y problemáticas acerca del tema de interés; después, se contrastó con algunos aportes teóricos. Para el instrumento se utilizó como guía inicial la propuesta de Cabero, Llorente y Puentes (2010) sobre la formación semipresencial, con algunas modificaciones según el contexto institucional y otras aportaciones de la literatura.

El instrumento final se conformó de 34 preguntas abiertas destinadas a abordar tres aspectos: 1) el enfoque tecnopedagógico, desde el cual se pretende abordar temáticas relacionadas con las condiciones de infraestructura tecnológica de la institución, 2) la capacitación docente que proporciona la institución y 3) la concepción acerca de buenas prácticas a través de plataformas y espacios virtuales.

Otra sección se conformó de aspectos culturales y temas referentes a estrategias colaborativas, actitudes y creencias de actores, además de la motivación que asumen en torno a la enseñanza a través de tecnologías; algunos de los autores que han permitido estructurar este enfoque son Fink y Hargreaves (2006), Hannan y Silver (2005) y Fullan y Stiegelbauer (2011). Para la dimensión conformada desde la perspectiva sociopolítica, autores como Brunner (2000), Cox (2002), Day (2013) permitieron la configuración de una sección que contempla temas relacionados con estímulos e incentivos para participar en la educación semipresencial; también sobre el compromiso y el liderazgo que asumen los actores en la modalidad (ver figura 1). 

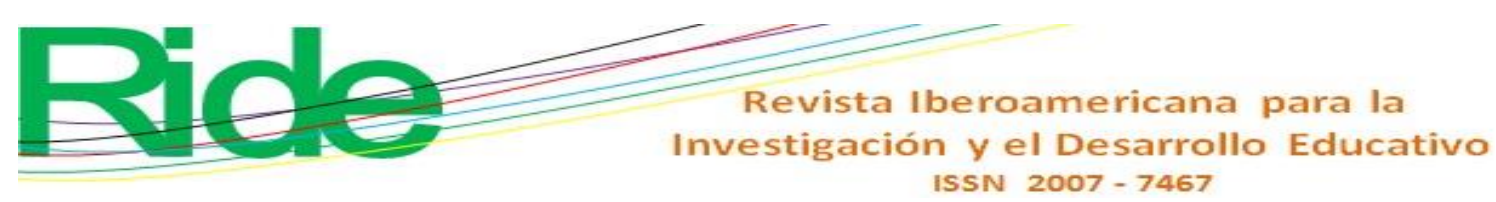

Figura 1. Categorías iniciales de análisis

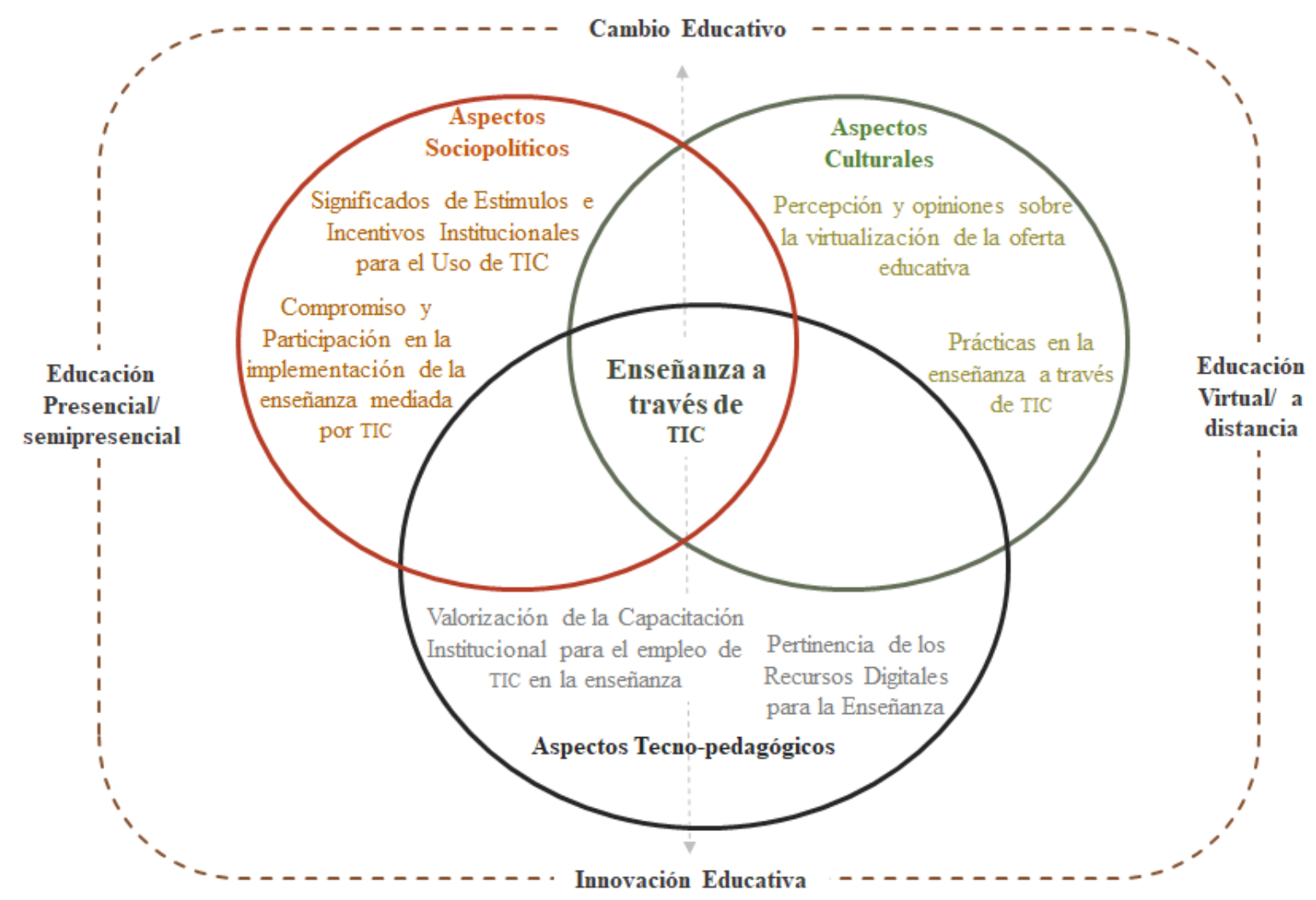

Fuente: Elaboración propia

Con base en este instrumento, se entrevistó durante el mes de septiembre de 2019 a 32 docentes adscritos a diferentes unidades académicas. Inicialmente en San Luis Río Colorado (sede principal de la institución), Hermosillo y Magdalena (unidades con mayor matrícula de estudiantes). Finalmente, se aplicó en sedes ubicadas en otras dos ciudades: Villa Juárez y Navojoa. Una vez recolectados los datos, el análisis se llevó a cabo desde una triangulación hermenéutica, entendida como un procedimiento de reunión y cruce dialéctico de información y que, en términos de Cisterna (2005), implica un seleccionar la información por estamentos, triangular la información entre estamentos y posteriormente con el marco teórico.

A partir de la transcripción de las entrevistas, se inició el análisis con el apoyo del software Atlas.ti. Primero, se realizó una selección de la información que permitió identificar los elementos pertinentes de acuerdo con los objetivos de investigación. En cada entrevista se realizó un ejercicio de codificación para agrupar temáticas que permitieran identificar, resumir y sintetizar lo que expresó cada uno de los informantes. Este ejercicio permitió, entonces, establecer códigos en cada una de las entrevistas. Posterior a esto, se llevó a cabo 

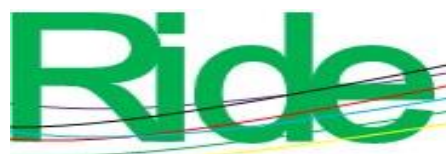

Revista Iberoamericana para la Investigación y el Desarrollo Educativo ISSN $2007-7467$

una triangulación entre estamentos (Cisterna, 2005), lo que implicó identificar y clasificar a los códigos que se relacionaban o apuntaban a un mismo tema entre la totalidad de las entrevistas. Es decir, se agruparon todos los códigos que señalaban información sobre un mismo tema, lo cual permitió la conformación de subcategorías.

Los resultados de cada subcategoría fueron contrastados con referentes teóricos para identificar situaciones que se advierten desde la literatura. Por otro lado, también se identificaron elementos que no habían sido contemplados previamente, como en los testimonios que señalan a la formación previa de los estudiantes como un obstáculo para desarrollar, de manera eficaz, la enseñanza a través de tecnologías. Este ejercicio de revisión de subcategorías y contrastación de información permitió rediseñar las categorías preestablecidas. Así pues, la información se estructuró de la siguiente manera (ver tabla 1). 

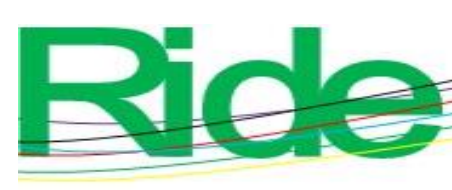

Revista Iberoamericana para la Investigación y el Desarrollo Educativo ISSN 2007 - 7467

Tabla 1.Relación de dimensiones, categorías y palabras clave del estudio.

\begin{tabular}{|c|c|c|c|}
\hline $\begin{array}{l}\text { Dimensión } \\
\text { de } \\
\text { observación }\end{array}$ & Categorías & Subcategorías & Palabras clave (códigos) \\
\hline \multirow[t]{7}{*}{$\begin{array}{l}\text { Tecnopedagó } \\
\text { gica }\end{array}$} & \multirow[t]{3}{*}{$\begin{array}{l}\text { Desvalorización } \\
\text { de TIC }\end{array}$} & $\begin{array}{l}\text { Limitado acceso a } \\
\text { infraestructura } \\
\text { tecnológica }\end{array}$ & $\begin{array}{l}\text { Equipamiento limitado, métodos } \\
\text { de adquisición de equipo, equipo } \\
\text { suficiente. }\end{array}$ \\
\hline & & $\begin{array}{l}\text { Sensación de poca } \\
\text { utilidad y mal } \\
\text { aprovechamiento de } \\
\text { equipo }\end{array}$ & $\begin{array}{l}\text { Equipamiento en buen estado, } \\
\text { necesidad de licencias de } \\
\text { software, equipo mal colocado en } \\
\text { las aulas. }\end{array}$ \\
\hline & & $\begin{array}{l}\text { Desvalorización de } \\
\text { plataforma virtual }\end{array}$ & $\begin{array}{l}\text { Desconocimiento sobre uso de } \\
\text { plataforma, desinterés por utilizar } \\
\text { la plataforma, preferencia por } \\
\text { modalidad tradicional. }\end{array}$ \\
\hline & \multirow[t]{2}{*}{$\begin{array}{l}\text { Sensación de } \\
\text { limitaciones } \\
\text { didácticas a través } \\
\text { del uso de TIC }\end{array}$} & $\begin{array}{l}\text { Inconformidad con } \\
\text { diseño de secuencias } \\
\text { didácticas }\end{array}$ & $\begin{array}{l}\text { Secuencias didácticas } \\
\text { desactualizadas, secuencias } \\
\text { didácticas poco flexibles, } \\
\text { secuencias didácticas pertinentes. }\end{array}$ \\
\hline & & $\begin{array}{l}\text { Percepción de la } \\
\text { educación virtual } \\
\text { como limitante para } \\
\text { la enseñanza a través } \\
\text { de la práctica }\end{array}$ & $\begin{array}{l}\text { Enseñanza centrada en el alumno, } \\
\text { planteamiento de ejemplos, } \\
\text { muestra de aplicación del } \\
\text { conocimiento, uso de TIC como } \\
\text { limitante. }\end{array}$ \\
\hline & \multirow[t]{2}{*}{$\begin{array}{l}\text { Problemáticas de } \\
\text { planeación en la } \\
\text { capacitación } \\
\text { docente }\end{array}$} & $\begin{array}{l}\text { Capacitación } \\
\text { desactualizada }\end{array}$ & $\begin{array}{l}\text { Falta de instructores expertos en } \\
\text { el área, necesidad de nuevas } \\
\text { capacitaciones, sensación de } \\
\text { desapego de capacitación con } \\
\text { necesidades docentes. }\end{array}$ \\
\hline & & $\begin{array}{l}\text { Incompatibilidad } \\
\text { entre horarios de }\end{array}$ & $\begin{array}{l}\text { Problemáticas con horarios de } \\
\text { capacitación, sensación de poca } \\
\text { utilidad de capacitación, }\end{array}$ \\
\hline
\end{tabular}




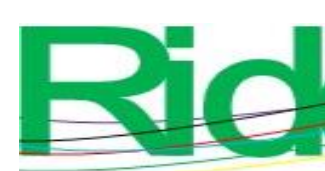

Revista Iberoamericana para la Investigación y el Desarrollo Educativo ISSN $2007-7467$

\begin{tabular}{|c|c|c|c|}
\hline & & $\begin{array}{l}\text { capacitación y carga } \\
\text { académica }\end{array}$ & $\begin{array}{l}\text { desinterés por el contenido de los } \\
\text { cursos. }\end{array}$ \\
\hline \multirow[t]{4}{*}{ Cultural } & \multirow[t]{2}{*}{$\begin{array}{l}\text { Inclinación hacia } \\
\text { la educación } \\
\text { presencial- } \\
\text { tradicional }\end{array}$} & $\begin{array}{l}\text { Preferencia por la } \\
\text { enseñanza } \\
\text { presencial- } \\
\text { tradicional }\end{array}$ & $\begin{array}{l}\text { Obligatoriedad de plataforma } \\
\text { como limitante, mayor tiempo de } \\
\text { estudio al estudiante, falta de } \\
\text { equipamiento, desinterés de } \\
\text { docentes por enseñanza virtual. }\end{array}$ \\
\hline & & $\begin{array}{l}\text { Sensación de baja } \\
\text { calidad educativa en } \\
\text { modalidades no } \\
\text { presenciales }\end{array}$ & $\begin{array}{l}\text { Sensación de baja calidad } \\
\text { educativa en modalidad virtual, } \\
\text { preferencia por educación } \\
\text { presencial-tradicional, motivación } \\
\text { por modalidad presencial. }\end{array}$ \\
\hline & \multirow[t]{2}{*}{$\begin{array}{l}\text { Resistencia al } \\
\text { cambio educativo } \\
\text { e innovación a } \\
\text { través de TIC }\end{array}$} & $\begin{array}{l}\text { Resistencia al } \\
\text { cambio educativo a } \\
\text { través de TIC }\end{array}$ & $\begin{array}{l}\text { Resistencia al cambio, motivación } \\
\text { por uso de TIC, desmotivación } \\
\text { por falta de capacitación, } \\
\text { sensación de falta de apoyo entre } \\
\text { colegas, sensación de apoyo } \\
\text { suficiente entre colegas. }\end{array}$ \\
\hline & & $\begin{array}{l}\text { Desinterés por } \\
\text { innovar en la } \\
\text { enseñanza a través } \\
\text { de TIC }\end{array}$ & $\begin{array}{l}\text { Desinterés por empleo de TIC, } \\
\text { interés por empleo de TIC, } \\
\text { inconformidad con equipamiento. }\end{array}$ \\
\hline \multirow[t]{2}{*}{ Sociopolítica } & \multirow[t]{2}{*}{$\begin{array}{l}\text { Percepción } \\
\text { negativa y } \\
\text { desconocimiento } \\
\text { sobre programas } \\
\text { de estímulos } \\
\text { institucionales }\end{array}$} & $\begin{array}{l}\text { Desconocimiento de } \\
\text { programas de } \\
\text { incentivos } \\
\text { institucionales }\end{array}$ & $\begin{array}{l}\text { Desconocimiento sobre programas } \\
\text { de incentivos, necesidad de } \\
\text { incentivo evaluador para el uso de } \\
\text { TIC, desvinculación de programas } \\
\text { de estímulo con objetivos de } \\
\text { calidad educativa de la institución. }\end{array}$ \\
\hline & & $\begin{array}{l}\text { Percepción negativa } \\
\text { acerca de la } \\
\text { comunicación con } \\
\text { directivos }\end{array}$ & $\begin{array}{l}\text { Capacitaciones entre colegas, } \\
\text { poca comunicación entre } \\
\text { profesores, comunicación con } \\
\text { directivos necesaria, falta de }\end{array}$ \\
\hline
\end{tabular}




\begin{tabular}{|c|c|c|}
\hline & \multicolumn{2}{|c|}{$\begin{array}{l}\text { Revista Iberoamericana para la } \\
\text { Investigación y el Desarrollo Educativo } \\
\text { ISSN } 2007-7467\end{array}$} \\
\hline & & $\begin{array}{l}\text { atención a opiniones de } \\
\text { profesores, evaluación al } \\
\text { desempeño docente como } \\
\text { condicionante. }\end{array}$ \\
\hline \multirow[t]{2}{*}{$\begin{array}{l}\text { Escaso } \\
\text { seguimiento a } \\
\text { propuestas e } \\
\text { inquietudes del } \\
\text { personal docente }\end{array}$} & $\begin{array}{l}\text { Problemáticas } \\
\text { relacionadas con el } \\
\text { diseño de secuencias } \\
\text { didácticas }\end{array}$ & $\begin{array}{l}\text { Elaboración de secuencias por } \\
\text { profesores inexpertos, falta de } \\
\text { capacitación sobre elaboración de } \\
\text { secuencias, elaboración de } \\
\text { secuencias entre colegas. }\end{array}$ \\
\hline & $\begin{array}{l}\text { Incertidumbre en } \\
\text { relación con el } \\
\text { seguimiento de } \\
\text { propuestas otorgadas } \\
\text { en academias }\end{array}$ & $\begin{array}{l}\text { Falta de atención a comentarios } \\
\text { hechos en academias, sensación } \\
\text { de trabajo en forma de reporte en } \\
\text { academias, percepción sobre poco } \\
\text { interés en profesores por atender } \\
\text { problemáticas en academias. }\end{array}$ \\
\hline
\end{tabular}

\section{Fuente: Elaboración propia}

Finalmente, los resultados fueron categorizados a partir de los testimonios analizados, de tal forma que, para este este texto, se han retomado los resultados que conformaron las categorías: "Desvalorización de TIC", "Limitaciones didácticas a través de TIC", "Percepción negativa sobre estímulos institucionales" y "Resistencia al cambio educativo".

\section{Resultados}

Antes que nada es pertinente señalar que toda revisión de la información recolectada se realiza desde una postura imparcial. Esto implica reconocer que el empleo de tecnologías en la educación puede traer tantos beneficios como problemáticas, según la forma de llevar a cabo el proceso de implementación y según cómo sea sea interiorizada por los actores involucrados.

En ese sentido, el análisis sobre las limitaciones y alcances de las tecnologías en la enseñanza se realiza a través de interrogantes que permiten profundizar y no solamente describir sucesos. Desde esta postura, se identificó que los informantes señalan a la capacitación docente, la conectividad a Internet en la institución, la incertidumbre sobre el uso de la plataforma digital, la resistencia al cambio y el desconocimiento de los programas 


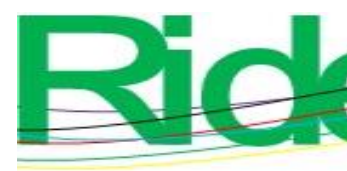

\section{Revista Iberoamericana para la Investigación y el Desarrollo Educativo ISSN $2007-7467$}

Aunado a lo anterior, estos testimonios permiten inferir que, a pesar de que las capacitaciones se han llevado a cabo, aún perviven dudas sobre los beneficios y la manera de utilizar las TIC para contribuir al mejoramiento de la enseñanza. Respecto a este punto, Ducoing (2003) subrayó la pertinencia de tomar en cuenta el contexto de la institución al momento de impartir una capacitación, la cual debe responder a las necesidades particulares de los académicos, según sus circunstancias y lo que se pretenda mejorar. En este sentido, se puede configurar una situación en dirección contraria a las recomendaciones de la Unesco (2006): proporcionar a los profesores capacitaciones en las que, además de prepararlos para el empleo del equipamiento tecnológico en el aula, también se enfatice sobre su uso pedagógico, al igual que en la intervención del diseño, la adaptación del currículo y en el desarrollo de materiales digitales para su uso en la enseñanza.

Por otro lado, se ubicaron aspectos por demás negativos y necesidades que refieren a hacer reuniones con colegas para esclarecer dudas y atenderlas en función de las necesidades de los docentes. Entre los testimonios destaca que no es tomada en cuenta la opinión del profesorado por sus superiores (personal directivo), así como la falta de un seguimiento sobre su progreso después de una capacitación. Además, se afirma que no participan en ningún programa de estímulos al desempeño docente por falta de tiempo y capacitación, y que la evaluación que los estudiantes hacen a los profesores influye en sus actividades docentes.

Hacen falta más reuniones entre nosotros para organizarnos mejor y resolver dudas porque los cursos que nos dan son buenos, pero no hay forma de recibir una retroalimentación y a veces a algunos profesores se les olvidan las cosas se vieron en el curso (Informante 15, Hermosillo)

Se nos ha capacitado en cursos sobre el modelo educativo, así como en el uso de la plataforma digital, pero hace falta entrenamiento sobre la realización de foros de discusión académica con estudiantes y colegas profesores (Informante 1, San Luis Río Colorado).

A partir de estos hallazgos, se concibe la necesidad de un programa que proporcione asesoría pertinente y contribuya con el aprovechamiento adecuado de las tecnologías en la práctica docente, lo cual es una preocupación legítima y además favorecedora (Marcelo, 2013). Sin embargo, tales señalamientos también permiten interpretar una realidad un tanto difusa en relación con la capacitación docente. Además, dan pie a otros cuestionamientos que 


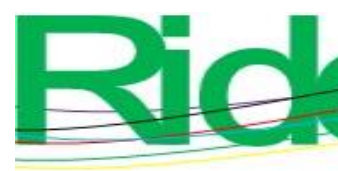

Revista Iberoamericana para la Investigación y el Desarrollo Educativo ISSN $2007-7467$

van más allá de si el docente fue capacitado; se extienden hacia si se ha mejorado la práctica docente a través del uso de las tecnologías.

Contrariamente, la creencia de algunos de los docentes es que las tecnologías pueden contribuir a mejorar la enseñanza y que, aun cuando los cursos no tienen continuidad a través de una retroalimentación, estiman que hace falta una modificación de sus cursos, lo cual deja entrever cierto interés por parte del profesorado en aprender a partir de un proceso adecuado de capacitación. A su vez, y al contrastar estos testimonios con los planteados anteriormente, se puede advertir que hay un punto en común: la capacitación. Cuando pareciera que los docentes no siempre se sienten motivados a usar las tecnologías por una cuestión generacional, tal vez esto no necesariamente sea así, tal vez no tiene que ver con la edad, sino con una capacitación poco estimulante y a veces desvinculada de los intereses propios del profesorado.

En ese sentido, en cuanto a las motivaciones que ofrece la institución para promover el empleo de tecnologías en el ejercicio docente, los informantes señalaron que la evaluación docente realizada por los estudiantes perjudica a los profesores de asignatura para luego ser contratados nuevamente; a razón de esto, algunos profesores modifican su ejercicio docente en función de lo que consideran ayudará a obtener una buena calificación del estudiante, aunque también hay quienes no tienen conocimiento de estos programas de incentivos en la institución.

Aquí no hay programas de incentivos que tengan que ver con el uso de tecnologías, antes te apoyaban para ir a diplomados y capacitarte, pero ya no, y los programas que hay solo son para investigación (Informante 7, San Luis Río Colorado)

Me parecen bien porque si un grupo de estudiantes a los que di clase pasan el Ceneval nos dan un bono extra, pero también hay otros como el [Programa para el Desarrollo Profesional Docente, para el Tipo Superior] Prodep, pero no sé cómo funciona (Informante 22, Magdalena).

La evaluación influye mucho porque tienes que caerle bien a los estudiantes ya que eso es lo que evalúan a veces no se fijan en cómo diste la clase o qué tanto te preparaste y si eres de horas sueltas y los estudiantes no te aprueban entonces ya no te vuelven a contratar (Informante 13, Hermosillo). 


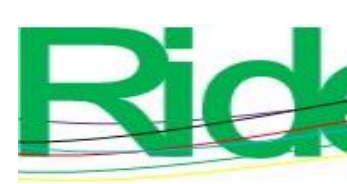

Revista Iberoamericana para la
Investigación y el Desarrollo Educativo
ISSN $2007-7467$

Este tipo de comentarios permiten suponer un distanciamiento de las intenciones para la innovación en la enseñanza que se establecen en la institución, pues, como argumenta López (2015), cada institución es diversa y tiene particularidades propias en cuanto a su funcionamiento, asumirlas como tal permite un acercamiento a la realidad que se vive en la educación superior.

No obstante, también se puede reconocer que algunos profesores consideran que la institución no otorga estímulos, lo cual puede redundar en la ausencia de una motivación; o por el contrario, hay un desconocimiento sobre cómo recibir incentivos para adecuar su práctica a los objetivos de la institución. Como sea que fuere, ambos casos son alarmantes, en especial si se asumen a los incentivos como catalizadores que posibilitan el cambio y el compromiso del docente con lo que se pretende innovar (Parra, Gómez y Pintor, 2014). En la UES, esto va todavía más allá, y es que mientras, por un lado, algunos profesores no han logrado identificar la existencia de programas de estímulos, por el otro, para quienes sí lo han hecho dichos programas han tenido efectos negativos que han impactado cuando menos indirectamente en el uso de tecnologías.

Un ejemplo de esto es el programa de compensación salarial que contempla como condicionante que la calificación del alumnado, proporcionada por el profesor, supere un promedio de 8.4 en el semestre y, además, que los estudiantes señalen como satisfactorio el desempeño del profesor en la asignatura (UES, 2021). Este último punto se ve reflejado mayormente en profesores de asignatura que son contratados por tiempo determinado, ya que cumplir con los criterios señalados es necesario para su continuidad laboral en la institución.

En general, tanto profesores que se encuentran interesados en una compensación salarial como quienes pretenden continuar realizando docencia en la institución tienen la exigencia de adaptar sus criterios de desempeño y de evaluación; entonces, el uso de tecnologías se encuentra permeado, en algunos casos, por la intención de generar simpatía en los estudiantes para obtener notas satisfactorias entre sí, y esto generalmente no se encuentra vinculado con aspectos pedagógicos que permitan un mejor desarrollo de la enseñanza. Más bien, se generan conflictos de interés que desmotivan al profesor, lo que ocasiona que antes de preguntarse cómo utilizar las tecnologías adecuadamente para sacar provecho, primero se cuestione qué hacer para no recibir una mala evaluación por parte del estudiante. 


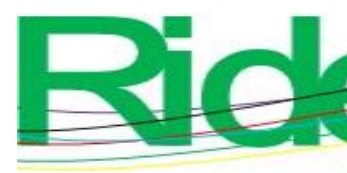

Revista Iberoamericana para la Investigación y el Desarrollo Educativo ISSN 2007 - 7467

La situación anterior deja entrever una necesidad de repensar las estrategias de incentivos por parte de la institución; también difundir los programas con el fin de que más profesores adecuen sus prácticas en función de los objetivos institucionales. Así, la inversión en infraestructura tecnológica que se realiza podrá favorecer tanto en el aumento de matrícula como en mejorar la enseñanza.

El empleo de las tecnologías en la enseñanza puede favorecer en el desarrollo de diferentes escenarios, cada uno con diferentes características. Algunos profesores de la UES, quienes cuentan con equipamiento tecnológico, pero no tienen el interés de utilizarlo, ocupan uno de estos escenarios; otro más se conforma a raíz de la falta de capacitación, o por el poco interés y su creencia de que las tecnologías no llegan a mejorar lo que se hace tradicionalmente en el aula. Este tipo de situaciones dejan ver un problema más complejo, ya que las limitaciones para usar tecnologías en la enseñanza se muestran en diferentes rutas.

Otro de los aspectos destacables tiene que ver con la supuesta obligatoriedad del empleo de tecnologías en la institución, ya que se ha propuesto el uso de una plataforma virtual en todas las asignaturas de la institución. Sin embargo, no hay supervisión sobre cómo los profesores utilizan estos sistemas, a tal grado de suponerse que hay quienes definitivamente no utilizan. Al respecto, Trepule, Tereseviciene y Rutkiene (2015) han advertido condiciones necesarias para utilizar efectivamente las tecnologías en los procesos de enseñanza. Por un lado, sugieren centrarse en las necesidades de aprendizaje del estudiante, ya que profesores con procedimientos más constructivistas tienen más posibilidades de generar un ambiente positivo de aprendizaje. Por el otro, recomiendan reconocer ventajas como la posibilidad de acceder a la información y limitaciones como la poca interacción que permite con los estudiantes. En cualquiera de las variantes cada profesor requiere esforzarse para comprender las necesidades formativas del estudiante.

Ahora bien, no hay que olvidar la exigencia para el profesorado de interactuar con el estudiante de manera virtual. De acuerdo con Ducoing (2020), la interacción entre profesor y estudiante resulta uno de los elementos indispensables que pueden mejorar en gran medida lo que se instruye. A pesar de ello, en las modalidades de enseñanza no presencial apoyada por tecnologías, los debates entre compañeros, el intercambio de ideas entre profesor y estudiante y las actividades de interacción parecen ser un poco menos frecuentes que en la enseñanza presencial. Este es un tema que se requiere atender en las instituciones: desde el diseño curricular y las orientaciones didácticas que se establecen en un modelo educativo 


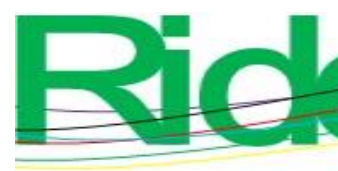

Revista Iberoamericana para la
Investigación y el Desarrollo Educativo
ISSN $2007-7467$

determinado hasta la planeación de las capacitaciones que se otorgarán a los profesores. En ese sentido, la institución requiere tomar en cuenta las necesidades para ofrecer constantemente cursos de capacitación. En general, estrategias que permitan ampliar las posibilidades de la enseñanza en entornos virtuales.

\section{Un escenario emergente: la educación superior en tiempos de pandemia}

Una problemática que se relaciona de manera directa con la situación expuesta tiene que ver con el escenario actual en que se encuentra la educación superior a nivel mundial, y que fue generada por la contingencia sanitaria debido a la enfermedad por coronavirus de 2019 (covid-19) (Moreno, 2020). Un escenario sin precedentes que tiene el potencial de marcar un antes y un después en el ejercicio docente (Bravo y Magis, 2020).

En el contexto mexicano, el 14 de marzo del año 2020, la Secretaría de Educación Pública (SEP) emitió una medida preventiva con el propósito de mitigar contagios, lo cual implicó cesar las actividades educativas de manera presencial en todos los niveles educativos; el regreso a clases se dio de manera virtual. Los efectos, opiniones y posturas que esto generó fueron un tanto diversos y hasta el momento no es posible asumir que la totalidad del personal académico se haya logrado adaptar a esta nueva normalidad.

Díaz-Barriga (2020) afirma que la capacitación docente para atender las necesidades educativas desde entornos virtuales otorgada por la SEP se ha enfocado en instruir acerca del diseño de objetos de aprendizaje y sesiones de trabajo en línea a través del empleo de las herramientas que ofrece la tecnología, lo cual ha reducido a la profesión docente a un técnico que eligen materiales para trabajar con sus estudiantes, es decir, para efectos de estas capacitaciones no se han analizado ni las condiciones del profesorado ni de las familias. En definitiva, cada docente se ha visto en la necesidad de aprender desde el aislamiento tanto los mecanismos técnicos de la educación virtual que no le hayan quedado claros como el diseño de nuevas formas de enseñar a través de herramientas que no todos estaban acostumbrados a utilizar, lo cual ha generado posturas, inquietudes e inconformidades diversas que hacen evidente la necesidad de llevar a cabo medidas que tomen en cuenta las necesidades del profesorado (Ruiz, 2020).

Lo que se pretende rescatar con estos señalamientos es una especie de contrastación entre el escenario actual de la educación y los resultados de este trabajo de investigación que dejan ver ideas, inquietudes y posturas diversas con respecto a la pertinencia de la tecnología 


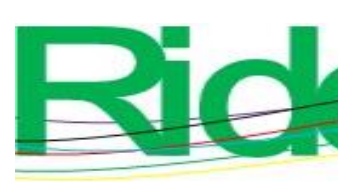

Revista Iberoamericana para la Investigación y el Desarrollo Educativo ISSN 2007 - 7467

estudios previos relacionados con este tema $\mathrm{y}$, por lo tanto, confirmar algunas de las aproximaciones que permiten comprender el objeto de estudio.

Tal es el caso de las problemáticas en los programas de estímulos institucionales. Luzardo, Sandia, Aguilar, Macias y Herrera (2017) afirman que uno de los elementos clave en el proceso de implementación de una innovación que contemple el uso de tecnologías en una institución educativa implica definir adecuadamente una estrategia institucional que contemple una planificación previa de las acciones que se van a realizar, donde también se hagan explícitos los propósitos y el valor que tiene, para la institución, la implementación de la innovación planteada. Bajo esta misma lógica es que Loor y García (2020) sugieren que las instituciones educativas pueden diseñar programas de incentivos que, además de generar motivación, permitan al personal comprender lo que se espera lograr con cada innovación.

Asimismo, Navarrete y Mendieta (2018), a través de un estudio orientado a indagar sobre la integración de las TIC en el contexto educativo ecuatoriano, encontraron que aún existen varios profesores que no están dispuestos a utilizar las tecnologías, pero que, además, siguen mostrando prácticas tradicionales que no están acordes a los nuevos escenarios y demandas actuales de la educación. En complemento, y desde una perspectiva un tanto más local, Palomino, Olivas, Robles y Pestaño (2014) recuperaron información a través de un cuestionario sobre el modelo educativo de la UES que fue aplicado a egresados, quienes señalaron como insuficiente tanto la diversificación de secuencias didácticas como el acceso a internet en la institución.

No obstante, este texto también deja ver algunas diferencias con otras investigaciones y que van de la mano con las particularidades del contexto institucional que se ha analizado. Esto, a su vez, representa un conjunto de elementos que se sugiere profundizar a través de nuevos estudios orientados a indagar sobre dos temáticas principales: la evaluación estudiante-docente en contextos virtuales y la factibilidad de una enseñanza innovadora a través de tecnologías en el contexto mexicano.

Respecto a la evaluación estudiante-docente, los testimonios dejan ver situaciones complejas que se deben repensar con el fin de identificar formas de reducir el sesgo por parte del estudiante, de tal manera que el profesorado tenga la posibilidad de aprovechar la evaluación para mejorar su ejercicio docente. Es un tema multidimensional que puede contemplar desde lo comentado anteriormente hasta las acciones institucionales en función de tal evaluación, es decir, ¿qué tan favorecedor será para una institución condicionar la 


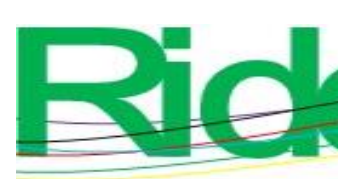

Revista Iberoamericana para la Investigación y el Desarrollo Educativo ISSN $2007-7467$

permanencia de los profesores de asignatura en función de una evaluación estudiantedocente? Reflexionar esto al momento de indagar sobre estrategias de enseñanza a través de tecnologías puede favorecer la visualización de nuevas formas de mejorar la relación estudiante-docente en contextos educativos virtuales.

En cuanto a la factibilidad de una enseñanza innovadora a través de tecnologías en el contexto mexicano se debe reconocer, en primer lugar, que aun cuando la educación apoyada por tecnologías, e incluso las modalidades de enseñanza no presenciales, representan una tendencia que va en aumento en las universidades de México, la educación básica y media superior son todavía impartidas predominantemente a través de modalidades educativas presenciales. Esto hace necesario indagar qué tan preparados están los estudiantes para enfrentar los desafíos que representan las modalidades ofertadas en las instituciones de educación superior, o bien las estrategias institucionales que contemplan el uso de tecnologías en la docencia pero desde la perspectiva del estudiante. Resulta fundamental, entonces, recuperar información acerca de lo que se hace en las instituciones para preparar al estudiante con respecto a la modalidad educativa en la que se encuentra inscrito y proporcionar sugerencias que reorienten las estrategias institucionales sobre el empleo de tecnologías.

\section{Conclusiones}

La formación en las universidades se ha orientado cada vez más hacia una oferta híbrida que contempla el uso de tecnologías como eje central para su funcionamiento. En consecuencia, las instituciones se encuentran en la necesidad constante de invertir en infraestructura tecnológica, pero además en la de adaptar sus modelos educativos para aprovechar algunos de los beneficios que pueden ofrecer las tecnologías al ejercicio docente. Esto implica, a su vez, capacitar a cada docente de tal forma que se comprenda cuándo, cómo y para qué utilizar las tecnologías. Tal situación ha generado una serie de retos que son enfrentados de manera diferente en cada una de las instituciones y que además generan diferentes resultados entre la percepción de cada docente. Lo anterior hace pertinente profundizar entre las experiencias del profesorado con respecto al uso de tecnologías.

En cuanto a la virtualidad como medio para el mejoramiento de la enseñanza, los testimonios recuperados en este documento dejan ver un escenario un tanto desalentador pero no por eso inmejorable. Por un lado, aun cuando algunos docentes tienen una percepción 


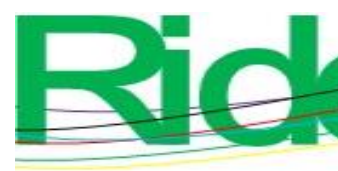

Revista Iberoamericana para la
Investigación y el Desarrollo Educativo
ISSN $2007-7467$

optimista sobre el uso de tecnologías, no parecen existir nociones que vinculen a la plataforma virtual con la adaptación de aspectos didácticos. En la institución, el ejercicio docente a través de la plataforma virtual se percibe como una actividad que requiere de una mejor capacitación, pero, a la vez, se asume que hay asignaturas que no se pueden llevar a cabo desde la virtualidad y esto no siempre es expuesto en relación con la falta de capacitación, de tal forma que algunos profesores observan a la virtualidad como limitante y la posibilidad de replantear las estrategias de enseñanza no siempre es atendida. Paralelamente, otro de los aspectos señalados apunta a la necesidad de una reconfiguración del programa de estímulos institucionales, de tal forma que el uso que se le da a las tecnologías dentro del aula sea incentivado.

Es necesario, además, que los profesores comprendan lo que se espera que realicen desde la perspectiva institucional y esto no parece ser comprendido de igual manera por todo el personal de la institución. Esto es: que las estrategias institucionales se conciban como un sistema que oriente a superar las limitaciones de la utilización de estos medios, independientemente de las modalidades educativas. Bajo la misma lógica, al pensar las tecnologías en el ámbito educativo, no solo es necesario estimular el uso, sino también la forma en que sean utilizadas. Es decir, las tecnologías no son únicamente equipos de computación, proyección, audio y software que se pueden adquirir para utilizarse de una manera indistinta, pues esto, en lugar de dar resultados positivos, se convierte en un proceso de desinformación y desviación de los propósitos de la enseñanza

Esta situación esperada se contrapone con una realidad diferente en la UES, la cual se advierte desde los testimonios analizados. Para contrarrestar, la universidad requiere planificar su programa de estímulos bajo una perspectiva más orientada a incentivar el uso esperado de las herramientas tecnológicas, pero también de las necesidades del personal docente. Paralelamente, una capacitación que permita la concepción de los objetivos propuestos en el programa de estímulos. Asimismo, es pertinente que se hagan explícitos tanto los requerimientos para participar como los incentivos de cada programa de estímulos en la institución, ya que algunas problemáticas que fueron señaladas apuntan al desconocimiento de los programas y permiten inferir cierta desmotivación al momento de implementar nuevos métodos de enseñanza. Mientras estos aspectos no sean atendidos, la concepción de una innovación a través del uso de tecnologías en la enseñanza continuará pareciendo un escenario lejano de alcanzar. 


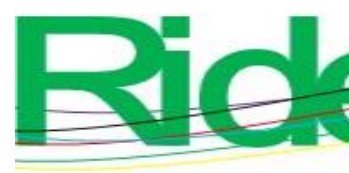

Revista Iberoamericana para la Investigación y el Desarrollo Educativo ISSN $2007-7467$

\section{Contribuciones a futuras líneas de investigación}

Durante el desarrollo de este trabajo fue posible identificar dos elementos temáticos que cruzan de manera transversal sobre el objeto de estudio. Para profundizar sobre el tema se considera pertinente complementar la información desde una indagación que aborde problemáticas acerca de la programación de horas virtuales que se utilizan en modalidades no presenciales, debido a que uno de los hallazgos recurrentes tiene que ver con una insatisfacción posible por parte de los profesores con las horas virtuales de una asignatura. Algunos profesores consideran que hace falta mayor supervisión a sus compañeros profesores para que las horas virtuales sean efectivas, ya que no se tiene claro la forma de desempeñarse en esos momentos.

Los testimonios van desde una sensación de aprovechamiento limitado en las funciones de la plataforma hasta percepciones de poca utilidad debido a la falta de capacitación;; en otros casos se señala que la implementación de las horas virtuales limita la enseñanza en las asignaturas más de tipo práctico, lo cual, en ciertos casos, es considerado indispensable e insustituible.

Otro tema emergente refiere a la situación del estudiante que ingresa a la educación superior, y en especial sus habilidades para desempeñarse en la virtualidad. Esta temática infiere un tema central que poco ha sido estudiado desde la perspectiva de la innovación educativa. En los análisis sobre los efectos de la enseñanza a través de tecnologías a veces pasa desapercibida la formación previa del estudiante, y entonces las instituciones tienden a implementar modalidades educativas diversas, incluso cuando hay estudiantes que durante toda su vida solo fueron educados en una misma modalidad, la presencial.

Así pues, en función de la información arrojada por los testimonios, fue posible identificar la pertinencia que tiene el autoaprendizaje para los estudiantes inscritos en la UES, lo cual se relaciona con el ejercicio docente, ya que los profesores manifiestan dificultades para interactuar con aquellos estudiantes que no están acostumbrados a trabajar en la virtualidad. Esto hace referencia a la ausencia de un hábito de autoaprendizaje, entendido como un obstáculo que complica el ejercicio docente debido a la sensación de que el estudiante sin experiencia en modalidades de educación virtual jamás llega a desarrollar esta capacidad. 


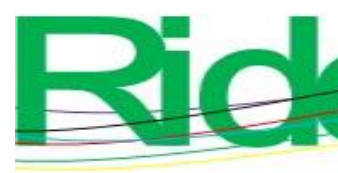

Revista Iberoamericana para la
Investigación y el Desarrollo Educativo
ISSN $2007-7467$

Por lo tanto, se recomienda que, aun cuando lo que se expone en este documento puede proporcionar pautas para mejorar la implementación de tecnologías en la enseñanza de la educación superior, se continúe con el estudio de las trayectorias, habilidades y requerimientos de los estudiantes para aprender en la educación virtual, solo así se podrá tener una perspectiva más amplia que, además, permitirá un mejor acercamiento para reconocer las posibilidades de éxito al hablar de una innovación educativa que propone apoyar el desempeño de la docencia.

\section{Referencias}

Allen, R. y Gupta, S. (2018). "Liderazgo académico" y las condiciones del trabajo académico. Literatura: Teoría, Historia, Crítica, 20(2), 293-319. Recuperado de https://dx.doi.org/10.15446/lthc.v20n2.70425.

Altbach, P. G. (2008). Funciones complejas de las universidades en la era de la globalización. En Global University Network for Innovation, La educación superior en el mundo (pp. 5-19). Madrid, España: Mundi Prensa.

Bautista, G., Borges, F. y Forés, A. (2006). Didáctica universitaria en entornos virtuales de enseñanza- aprendizaje. Madrid: Narcea, 245 pp. Recuperado de http://revistas.uned.es/index.php/ried/article/download/1001/918

Bravo, E. y Magis, C. (2020). La respuesta mundial a la epidemia del COVID-19: Los primeros tres meses. Boletín sobre COVID-19. 1(1), 3-8. Recuperado de http://dsp.facmed.unam.mx/wp-content/uploads/2013/12/COVID-19-No.1-03-Larespuesta-mundial-a-la-epidemia-del-COVID-19-los-primeros-tres-meses.pdf.

Brunner, J. J. (2000). Educación: escenarios del futuro. Nuevas tecnologías y sociedad de la información. Santiago, Chile: Programa de Promoción de la Reforma Educativa en América Latina y el Caribe. Recuperado de http://200.6.99.248/ bru487cl/files/PREAL_doc.pdf.

Cabero, J., Llorente, C. y Puentes, A. (2010). La satisfacción de los estudiantes en red en la formación semipresencial. Comunicar, 18(35), 149-157. Recuperado de https://www.redalyc.org/pdf/158/15815042018.pdf.

Chan, M. (2016). La virtualización de la educación superior en América Latina: entre tendencias y paradigmas. RED. Revista de Educación a Distancia, (48), 1-32. http://www.redalyc.org/articulo.oa?id=54743590001 


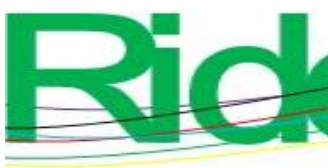

Revista Iberoamericana para la
Investigación y el Desarrollo Educativo
ISSN $2007-7467$

Cisterna, F. (2005). Categorización y triangulación como procesos de validación del conocimiento en investigaciones cualitativas. Theoría, 14(1), 61-71. Recuperado de https://www.redalyc.org/pdf/299/29900107.pdf.

Cobo, C. (2019). Acepto las condiciones. Usos y abusos de las tecnologías digitales. Madrid, España: Fundación Santillana.

Cox, C. (2003). Políticas educacionales en el cambio de siglo: la reforma del sistema escolar de Chile. Santiago, Chile: Editorial Universitaria.

Creswell, J. (2009). Research Design: Qualitative, Quantitative, and Mixed Methods Approaches. United States: SAGE

Day, C. (2013). El futuro de la educación en contextos de cambio educativo. Revista Mexicana de Investigación Educativa, 15(47), 1093-1145. Recuperado de http://www.scielo.org.mx/scielo.php?script=sci_arttext\&pid=S140566662010000400006.

De la Torre, S. (1998). Cómo innovar en los centros educativos. Estudio de casos. Madrid, España: Escuela Española.

De Vries, W. (2005). El cambio organizacional y la universidad pública. CPU-e. Revista de Investigación Educativa, (1), 1-16. Recuperado de http://www.uv.mx./cpue/num1/critica/cambioorganizacional.hml.

Díaz-Barriga, A. (2020). La escuela ausente, la necesidad de replantear su significado. En Casanova, H. (coord.), Educación y pandemia: una visión académica (pp. 19-29). Ciudad de México, México: Universidad Nacional Autónoma de México, Instituto de Investigaciones sobre la Universidad y la Educación.

Diez, Á., Aparici. R. y Gutiérrez, A. (2003). Nuevas tecnologías, educación y sociedad. Perspectivas críticas. Bilbao, España: Hegoa.

Ducoing, P. (2003). Sujetos, actores y procesos de formación. Tomo II. México: Consejo Mexicano de Investigación Educativa.

Ducoing, P. (2020). Una expresión de la desigualdad en educación básica durante la emergencia sanitaria: el caso de una alumna. En Casanova, H. (coord.), Educación y pandemia: una visión académica (pp. 55-64): Ciudad de México, México: Universidad Nacional Autónoma de México, Instituto de Investigaciones sobre la Universidad y la Educación. 


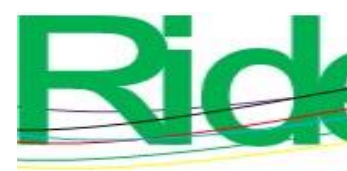

Revista Iberoamericana para la
Investigación y el Desarrollo Educativo
ISSN $2007-7467$

Espinosa, S. (2013). Informe de actividades del rector 2012-2013. Hermosillo, Sonora: Universidad Estatal de Sonora. http://www.ues.mx/Docs/conocenos/informacion_institucional/Informe\%20d\%20 Rector\%202013.pdf

Fink, D. y Hargreaves, A. (2006). Estrategias de cambio y mejora en educación caracterizadas por su relevancia, difusión y continuidad en el tiempo. Revista de Educación, (339), 43-58. Recuperado de https://dialnet.unirioja.es/servlet/articulo?codigo=2057197.

Fullan, M. y Stiegelbauer, S. (2011). El cambio educativo. Guía de planeación para maestros. México: Trillas

Guzmán, J. E., Muñoz, J. Álvarez, F. J. y Velázquez, C. E. (2014). La brecha digital en el estado de Aguascalientes. Investigación y Ciencia, (61). 52-61. Recuperado de http://www.redalyc.org/articulo.oa?id=67431579008.

Hannan, A. y Silver, H. (2005). La innovación en la enseñanza superior. Enseñanza aprendizaje y culturas institucionales. España: Narcea.

Huerta, H. (2016). Informe de Actividades 2016. Hermosillo, Sonora: Universidad Estatal de Sonora. Recuperado de http://www.ues.mx/docs/conocenos/informacion_institucional/INFORMEDEACTI VIDADES2016.pdf?0.18769138233343363.

Loor, M. y García, C. (2020). Uso de las TIC como estrategia de enseñanza para docentes de educación general básica en la zona rural. Revista Científica Dominio de las Ciencias 6(2), 748-763. Recuperado de http://dx.doi.org/10.23857/dc.v6i3.1246.

López, J., González, E. y López, R. (2018). Formación y uso de TIC en educación superior: opiniones del profesorado. CPU-e. Revista de Investigación Educativa, (27), 33-59. Recuperado de https://doi.org/10.25009/cpue.v0i27.2557.

López, M. (2015). Las nuevas tecnologías en el proceso de enseñanza y aprendizaje. ¿Qué piensan los futuros maestros? Tejuelo, 6(8), 40-61. Recuperado de http://hdl.handle.net/11162/98323.

Luzardo, M., Sandia, B., Aguilar, A., Macias, M. y Herrera, J. (2017). Factores que influyen en la adopción de las tecnologías de información y comunicación por parte de las universidades. Dimensión Enseñanza-Aprendizaje. Educere, 21(68), 143-153. Recuperado de https://www.redalyc.org/articulo.oa?id=35652744018. 


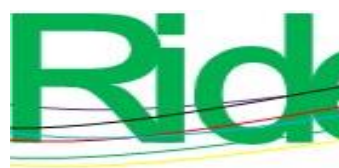

Revista Iberoamericana para la Investigación y el Desarrollo Educativo ISSN 2007 - 7467

Marcelo, C. (2013). Las tecnologías para la innovación y la práctica docente. Revista Brasileira de Educação, 18(52), 25-47. Recuperado de http://www.scielo.br/pdf/rbedu/v18n52/03.pdf.

Mejía, G. (2016). Las universidades públicas estatales de apoyo solidario: entre el aislamiento y la precariedad. Nexos. https://educacion.nexos.com.mx/?p=384

Mendoza, J. (2015). Ampliación de la oferta de educación superior en México y creación de instituciones públicas en el periodo 2001-2012. Revista Iberoamericana de Educación Superior, 6(16). Recuperado de https://doi.org/10.22201/iisue.20072872e.2015.16.149.

Moreno, S. (2020). La innovación educativa en los tiempos de coronavirus. Salutem Scientia Spiritus, 6(1). Recuperado de https://pesquisa.bvsalud.org/portal/resource/pt/biblio1087909.

Mungaray, A., Ocegueda, M. T., Moctezuma, P. y Ocegueda, J. M. (2016). La calidad de las Universidades Públicas Estatales de México después de 13 años de subsidios extraordinarios. Revista de la Educación Superior, 45(177), 67-93. Recuperado de https://dx.doi.org/10.1016/j.resu.2016.01.008.

Navarrete, G. y Mendieta, R. (2018). Las TIC y la educación ecuatoriana en tiempos de internet: Breve análisis. Espirales, 2(15). 123-136. Recuperado de https://www.revistaespirales.com/index.php/es/article/view/220/167.

Organización de las Naciones Unidas para la Educación, la Ciencia y la Cultura [Unesco]. (2006). La integración de las tecnologías de la información y la comunicación en los Sistemas Educativos. Buenos Aires, Argentina: Instituto Internacional de Planeamiento de la Educación. Recuperado de http://unesdoc.unesco.org/images/0015/001507/150785s.pdf.

Organización para la Cooperación y el Desarrollo Económico [OCDE]. (2016). Innovating Education and Educating for Innovation. The Power of Digital Technologies and Skills. Paris, France: OECD Publishing.

Palomino, R., Olivas, E., Robles, J. y Pestaño, F. (2014). La perspectiva del alumno egresado de la UES sobre el modelo educativo Enface. Revista Global de Negocios, 2(1), 6577. Recuperado de http://ssrn.com/abstract=2325145.

Parra, S., Gómez, M. y Pintor, M. (2014). Factores que inciden en la implementación de las TIC en los procesos de enseñanza-aprendizaje en $5 .^{\circ}$ de primaria en Colombia. 


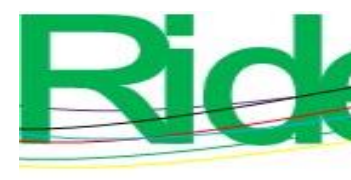

Revista Complutense de Educación, 26, 197-213. Recuperado de http://dx.doi.org/10.5209/rev_RCED.2015.v26.46483.

Rama, C. (2012). La reforma de la virtualización de la universidad. El nacimiento de la educación digital. Guadalajara, Jalisco: UDG Virtual

Ramírez, A. y Casillas, M. A. (comps.) (2014). Háblame de TIC. Tecnología digital en la educación superior. Córdoba, Argentina: Editorial Brujas. Recuperado de https://www.uv.mx/personal/albramirez/2014/08/01/hablamedetic/.

Rodríguez, R. (2002). Continuidad y cambio de las políticas de educación superior. Revista Mexicana de Investigación Educativa, 7(14), 131-154. Recuperado de http://www.redalyc.org/articulo.oa?id=14001407.

Rodríguez, J. R., Treviño, L. y Urquidi, L. E. (2007). La educación superior en Sonora, tendencias hacia la diversificación sectorial. Revista de la Educación Superior, 36(141), 23-39. Recuperado de http://www.scielo.org.mx/scielo.php?script=sci_arttext\&pid=S0185$27602007000100002 \& \operatorname{lng}=$ pt\&tlng=es.

Ruiz, E. (2020). La práctica docente universitaria en ambientes de educación a distancia. Tensiones y experiencias de cambio. En Casanova, H. (coord.), Educación y pandemia: una visión académica (pp. 109-113). Ciudad de México, México: Universidad Nacional Autónoma de México, Instituto de Investigaciones sobre la Universidad y la Educación.

Rubio, J. (coord.) (2006) La política educativa y la educación superior en México. 19952006: Un balance. México: Secretaría de Educación Pública-Fondo de Cultura Económico.

Sautu, R., Boniolo, P., Dalle, P y Elbert, R. (2005). Manual de metodología de investigación. Construcción del marco teórico, formulación de los objetivos y elección de la metodología. Buenos Aires, Argentina: Lumiere.

Silvio, J. (2006). Hacia una educación virtual de calidad, pero con equidad y pertinencia. RUSC. Universities and Knowledge Society Journal, 3(1). Recuperado de https://www.redalyc.org/pdf/780/78030106.pdf.

Suárez, V., Suárez, M., Oros, S. y Ronquillo, E. (2020). Epidemiología de COVID-19 en México: del 27 de febrero al 30 de abril del 2020. Revista Clínica Española, 220(8), 463-471. Recuperado de https://pubmed.ncbi.nlm.nih.gov/32560915/. 

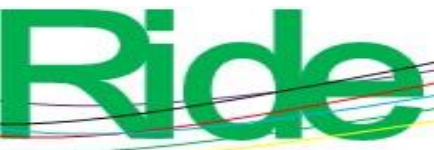

Revista Iberoamericana para la Investigación y el Desarrollo Educativo ISSN $2007-7467$

Trepule, E., Tereseviciene, M. and Rutkiene, A. (2015). Didactic Approach of Introducing Technology Enhanced Learning (TEL) Curriculum in Higher Education. ProcediaSocial and Behavioral Sciences, 191, 848-852. Retrieved from http://dx.doi.org/10.1016/j.sbspro.2015.04.340.

Turpo, O. (2013). Perspectiva de la convergencia pedagógica y tecnológica en la modalidad blended learning. Revista de Educación a Distancia, (39). Recuperado de https://revistas.um.es/red/article/view/234261.

Universidad Estatal de Sonora [UES]. (2021). Convocatoria Programa de Compensación Salarial. México: Universidad Estatal de Sonora. Recuperado de https://ues.mx/archivos/banners/0715Convocatoria_CompensacionSalarial2021_Of. .pdf. 


\begin{tabular}{|l|l|}
\hline Rol de Contribución & Autor (es) \\
\hline Conceptualización & $\begin{array}{l}\text { José Ricardo López Espinosa «igual» Edgar Oswaldo González } \\
\text { Bello «igual» }\end{array}$ \\
\hline Metodología & $\begin{array}{l}\text { José Ricardo López Espinosa «igual» Edgar Oswaldo González } \\
\text { Bello «igual» }\end{array}$ \\
\hline Software & $\begin{array}{l}\text { José Ricardo López Espinosa «igual» Edgar Oswaldo González } \\
\text { Bello «igual» }\end{array}$ \\
\hline Validación & $\begin{array}{l}\text { José Ricardo López Espinosa «igual» Edgar Oswaldo González } \\
\text { Bello «igual» Etty Haydee Estévez Nenninger «igual» Francisco } \\
\text { Javier Parra Bermúdez «igual» }\end{array}$ \\
\hline Análisis Formal & $\begin{array}{l}\text { José Ricardo López Espinosa «igual» Edgar Oswaldo González } \\
\text { Bello «igual» }\end{array}$ \\
\hline Investigación & José Ricardo López Espinosa «principal» \\
\hline Recursos & $\begin{array}{l}\text { José Ricardo López Espinosa «principal» Edgar Oswaldo } \\
\text { González Bello «principal» Doctorado en Innovación } \\
\text { Educativa, Universidad de Sonora «que apoya» }\end{array}$ \\
\hline Supervisión & José Ricardo López Espinosa «principal» \\
\hline Administración de Proyectos & Edgar Oswaldo González Bello «principal» \\
\hline Adquisición de fondos & $\begin{array}{l}\text { José Ricardo López Espinosa «igual» Edgar Oswaldo González } \\
\text { Bello «igual» }\end{array}$ \\
\hline Escritura - Preparación del & José Ricardo López Espinosa «principal» \\
\hline Escritura - Revisión y edición & Edgar Oswaldo González Bello «principal» \\
\hline Visualización & $\begin{array}{l}\text { José Ricardo López Espinosa «igual» Edgar Oswaldo González } \\
\text { Bello «igual» }\end{array}$ \\
\hline Edgar Oswaldo González Bello «principal» \\
\hline Cunal
\end{tabular}

